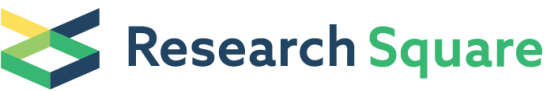 \\ Preprints are preliminary reports that have not undergone peer review. \\ They should not be considered conclusive, used to inform clinical practice, or referenced by the media as validated information.
}

\section{Impact of Different Waves of COVID-19 on Emergency Medical Services and Out-of-hospital Cardiopulmonary Arrest in Madrid, Spain}

Jose-María Navalpotro-Pascual

Servicio de Urgencia Médica de la Comunidad de Madrid, SUMMA 112, Madrid

Diana Monge-Martín

Facultad de Medicina, Universidad Francisco de Vitoria, Madrid

Manuel-José González-León

Servicio de Urgencia Médica de la Comunidad de Madrid, SUMMA 112, Madrid

Fernando Neria

Facultad de Medicina, Universidad Francisco de Vitoria, Madrid https://orcid.org/0000-0002-4417-2248

Francisco Peinado-Vallejo

Servicio de Urgencia Médica de la Comunidad de Madrid, SUMMA 112, Madrid

Carlos Alonso-Blas

Servicio de Urgencia Médica de la Comunidad de Madrid, SUMMA 112, Madrid

Belén Muñoz-Isabel

Servicio de Urgencia Médica de la Comunidad de Madrid, SUMMA 112, Madrid

Yago Muñecas-Cuesta

Servicio de Urgencias médicas de la Comunidad de Madrid, SUMMA 112, Madrid

Alfredo Carrillo-Freire

Servicio de Urgencia Médica de la Comunidad de Madrid, SUMMA 112, Madrid

Juan Les-González

Servicio de Urgencia Médica de la Comunidad de Madrid, SUMMA 112, Madrid

Alonso Mateos-Rodríguez ( $\sim$ Alonso.mateos@salud.madrid.org )

Servicio de Urgencia Médica de la Comunidad de Madrid, SUMMA 112, Madrid https://orcid.org/0000-0001-8281-9308

Original research

Keywords: Emergency Medical Services, Out of hospital cardiac arrest, COVID19

Posted Date: October 1st, 2021

DOI: https://doi.org/10.21203/rs.3.rs-944651/v1

License: (9) (1) This work is licensed under a Creative Commons Attribution 4.0 International License. Read Full License 


\section{Abstract}

Background: COVID-19 has led to decreased survival of out-of-hospital cardiorespiratory arrest (OHCA). We analysed the impact of the first COVID-19 pandemic year on emergency medical services and OHCA care compared with the previous year.

Methods: Data for this observational study were collected for OHCAs attended by the SUMMA 112 emergency service during March 2019 to March 2021. We compared data covering 15 March 2020-14 March 2021 (pandemic year) to retrospective data covering 15 March 2019-14 March 2020 (non-pandemic year).

Results: During the pandemic period, 1743 OHCA patients were attended, compared to 1781 during the non-pandemic year. Median patient age during the pandemic period was lower than in the non-pandemic period ( $71 \mathrm{vs} 72, p=0 \cdot 037$ ). Emergency services response activation time increased during the pandemic year, to 3 minutes, 16 seconds from 2 minutes, 48 seconds in the non-pandemic period $(p=0.001)$. Time to arrival at the scene also increased during the pandemic (12 minutes vs 11 minutes, 25 seconds before the pandemic; $p=0 \cdot 001)$. The percentage of OHCAs in which resuscitation was attempted was lower during the pandemic $(59 \cdot 4 \%$ vs $62.9 \%, p=0.034)$, as were survival on hospital arrival $(30.3 \%$ vs $34.6 \%, p=0.04)$. Differences in response activation time $(p=0.003)$ and scene arrival times $(p=0.003)$ were greater during the first pandemic wave compared with the later phases.

Conclusions: The different phases of the pandemic variably affected OHCA care. The first wave led to longer resource activation, increased home events and scene arrival times, as well as lower patient survival.

\section{Background}

A mere three months elapsed from the time the first COVID-19 cases were reported in December 2019, in Wuhan, China, until the World Health Organisation (WHO) declared a pandemic ${ }^{1}$ on 11 March 2020. In Spain, 31 cases had been confirmed by 28 February. By the time a state of alert was declared on 14 March, 2940 cases and 86 deaths had been reported in the Autonomous Community of Madrid, bringing the total for Spain to 5753 cases and 136 deaths. ${ }^{2}$ Since then, the disease has affected different countries and regions with peaks and troughs in cumulative incidence figures, referred to as pandemic waves.

Out-of-hospital cardiac arrest (OHCA) is one of the three leading causes of death in industrialised countries, affecting more than 370000 individuals in the United States and Europe. ${ }^{3,4}$ Several studies have described the impact of the first pandemic wave in terms of the number of cases and OHCA survival rates in various regions, ${ }^{5-6}$ but few have addressed the relationship between the successive phases and how they affected OHCA. ${ }^{7,8}$ Similarly, some publications have focused on how COVID-19 has affected the management of emergency medical service (EMS) calls and resources, ${ }^{9-10}$ but we have found none describing variations in these factors during different waves of the pandemic.

In Spain, the region hardest hit by the pandemic is the Autonomous Community of Madrid, with 603840 cases reported up to 15 March 2021. ${ }^{11}$ The 14-day cumulative incidence peaked at more than 990 cases, with these rates remaining above 200 for an eight-month period between 15 March 2020 and 15 March 2021.

Importance: these data will help EMS plan ahead for increases in calls, as well as offering insight into how OHCA and its epidemiology are affected by fluctuations during the course of a pandemic such as COVID-19. The utility could be immediate, given the new waves of COVID-19 developing worldwide as a result of emerging variants.

Goals of This Investigation: the objectives of the current study were twofold. First, we sought to describe how the different waves in the first pandemic year affected the healthcare activity of the Spanish EMS. Second, we compared the effects of the pandemic year on OHCA care to those of the preceding non-pandemic year in terms of initiating cardiopulmonary resuscitation (CPR) and survival in a community with a high incidence of COVID-19.

\section{Methods}

\section{Study design and setting}

This retrospective observational study included all OHCAs attended by the SUMMA 112 emergency medical services from 15 March 2019 to 14 March 2021. The data were divided into a pre-pandemic period from 15 March 2019 to 14 March 2020 and a pandemic period from 15 March 2020 to 14 March 2021. The pandemic year was further divided into four subperiods according to the 14-day cumulative

Page $2 / 12$ 
incidence: a first wave from 15 March 2020 to 14 May 2020, a plateau phase from 15 May to 3 August when the cumulative incidence was relatively low, a second wave from 4 August to 9 December, and a third wave from 10 December 2020 to 14 March 2021.

In the Autonomous Community of Madrid, Spain, SUMMA 112 is responsible for emergency medical care. The SUMMA 112 emergency coordinating centre, which is accessed by dialling 112 or 061, employs a two-tier call management system: a call handler first analyses the priority of the incoming call, and then a doctor validates the assessment and proposes the optimal healthcare resources.

\section{Selection of Participants}

All patients with OHCA who were attended by SUMMA 112 (regardless of whether a resuscitation attempt was made) during the study period were included in our analysis.

\section{Measurements}

SUMMA 112 maintains a permanent record of all OHCAs it attends. This record is incorporated into the Spanish Out-of-hospital Cardiorespiratory Arrest Registry (OHSCAR). The methods used for gathering OHSCAR data have been described previously. ${ }^{12}$ All variables were collected according to the definitions of the Utstein Resuscitation Register for OHCA. ${ }^{13}$ From that registry, we acquired data from 15 March 2019 to 14 March 2021. The OHSCAR registry has been approved by ethics committees in Northwestern Malaga, Aragon, Cáceres, Navarra, and the Basque Country. Informed consent was not required because the registry is anonymised. STROBE guidelines for data reporting were followed. ${ }^{14}$

\section{Analysis}

The variables collected were age, activation time, arrival time, sex, witnessed arrest, arrest location, bystander response, first monitored rhythm, pathogenesis, airway management and type, advanced life support and reason for not providing advanced life support, hospital admission with return of spontaneous circulation, overall survival to hospital discharge, and overall survival with a good neurological outcome. Neurological status was defined according to the Cerebral Performance Categories scale. ${ }^{12}$ Patients were categorised into one of the above-described periods according to the date of their OHCA.

Quantitative data are described using medians and interquartile ranges (IQRs) and the qualitative data with $\mathrm{n}$ and percentage values. Comparative analyses were performed using Pearson's chi-square test or Fisher's exact test for qualitative variables and the Wilcoxon test for quantitative variables. Differences were considered statistically significant when the p-value was less than 0.05 . All statistical analyses were performed using R software v 4.1.

\section{Results}

\section{Impact of the pandemic on OHCA}

During the pandemic year, 1743 patients with OHCA were attended, whereas in the non-pandemic study year, 1781 were attended. Table 1 shows a comparison of values between the two time periods. We found a decreased median (IQR) age from 72 (59-82) years prepandemic to $71(57-81)$ years during the pandemic $(p=0.037)$. Median activation time (the time of resource activation minus time of call in minutes:seconds) increased from 2:48 (1:30-6:01) pre-pandemic to 3:16 (1:33-8:17) during the pandemic $(p=0.001)$, as did arrival time (arrival time minus activation time), from $11: 25$ (8:14-15:30) to 12:00 (8:41-16:21; $p<0.001)$. Sex ratios did not differ $(603(33.9 \%)$ women, $626(36.0 \%)$ men; $p=0.19)$.

\section{Table 1}

Comparison of non-pandemic period/ pandemic period 


\begin{tabular}{|c|c|c|c|c|}
\hline & N & Pre-pandemic, $\mathrm{N}=1781(51 \%)^{1}$ & Pandemic, $N=1743(49 \%)^{1}$ & p-value ${ }^{2}$ \\
\hline Age (years) & 3522 & 72 [59-82] & $71[57-81]$ & 0.037 \\
\hline Activation time (min) & 3520 & $2: 48[1: 30-6: 01]$ & $3: 16[1: 33-8: 17]$ & 0.001 \\
\hline Arrival time (min) & 3503 & $11: 25$ [8:14-15:30] & $12: 00[8: 41-16: 21]$ & $<0.001$ \\
\hline Sex (female) & 3522 & $603(33.9 \%)$ & $626(36 \cdot 0 \%)$ & $0 \cdot 191$ \\
\hline Arrest location & 3516 & & & $<0.001$ \\
\hline Home & & $1407(79 \cdot 0 \%)$ & $1466(84 \cdot 5 \%)$ & \\
\hline Other & & $374(21 \cdot 0 \%)$ & $269(15 \cdot 5 \%)$ & \\
\hline Witnessed arrest & 3520 & $1443(81 \cdot 0 \%)$ & $1418(81 \cdot 5 \%)$ & 0.693 \\
\hline Prior CPR & 3524 & $708(39 \cdot 8 \%)$ & $693(39 \cdot 8 \%)$ & 0.997 \\
\hline Advanced CPR & 3518 & $1120(62 \cdot 9 \%)$ & $1033(59 \cdot 4 \%)$ & 0.034 \\
\hline Reason for no CPR & 1281 & & & $0 \cdot 104$ \\
\hline Arrest time unknown & & $175(27 \cdot 3 \%)$ & $180(28 \cdot 1 \%)$ & \\
\hline Excessive interval from collapse with no ALS & & $224(35 \cdot 0 \%)$ & $254(39 \cdot 6 \%)$ & \\
\hline Status biologically compromised/other & & $241(37 \cdot 7 \%)$ & $207(32 \cdot 3 \%)$ & \\
\hline Shockable rhythm over aCPR & 2135 & $167(15 \cdot 0 \%)$ & $155(15 \cdot 1 \%)$ & 0.946 \\
\hline Airway isolation over aCPR & 2094 & $966(88 \cdot 1 \%)$ & $875(87 \cdot 7 \%)$ & $0 \cdot 745$ \\
\hline Type of isolation & 1791 & & & $<0.001$ \\
\hline Orotracheal tube & & $780(82 \cdot 6 \%)$ & $642(75 \cdot 8 \%)$ & \\
\hline Supraglottic airways & & $157(16 \cdot 6 \%)$ & $201(23 \cdot 7 \%)$ & \\
\hline Other & & $7(0 \cdot 7 \%)$ & $4(0 \cdot 5 \%)$ & \\
\hline Aetiology over CPRa & 2148 & & & 0.021 \\
\hline Medical & & $1000(89 \cdot 4 \%)$ & $951(92 \cdot 3 \%)$ & \\
\hline Non-medical & & $118(10 \cdot 6 \%)$ & $79(7 \cdot 7 \%)$ & \\
\hline Survival over CPRa & 2152 & & & 0.037 \\
\hline Yes & & $387(34 \cdot 6 \%)$ & $313(30 \cdot 3 \%)$ & \\
\hline No & & $733(65 \cdot 4 \%)$ & $719(69 \cdot 7 \%)$ & \\
\hline Hospital discharge over CPRa & 1873 & & & 0.075 \\
\hline Deceased & & $861(87 \cdot 1 \%)$ & $793(89 \cdot 7 \%)$ & \\
\hline Alive & & $128(12 \cdot 9 \%)$ & $91(10 \cdot 3 \%)$ & \\
\hline One-month status over CPRa & 1798 & & & $0 \cdot 057$ \\
\hline Deceased & & $824(87 \cdot 5 \%)$ & $773(90 \cdot 3 \%)$ & \\
\hline Alive & & $118(12 \cdot 5 \%)$ & $83(9 \cdot 7 \%)$ & \\
\hline \multicolumn{5}{|l|}{${ }^{1}$ Median [IQR]; n (\%) } \\
\hline \multicolumn{5}{|c|}{${ }^{2}$ Wilcoxon rank sum test; Pearson's Chi-squared test; Fisher's exact test } \\
\hline $\mathrm{CPR}=$ Cardiopulmonary resuscitation; $. \mathrm{aCPR}=$ & Advance & d cardiopulmonary resuscitation & & \\
\hline
\end{tabular}


neither did CPR attempts before EMS arrival (708 (39.8\%) pre-pandemic vs 693 (39.8\%) during the pandemic; $p=0.997)$.

In the pandemic year, the percentage of advanced CPR attempts compared to the total number of OHCAs attended was lower than in the previous year (1120 (62.9\%) vs $1033(59.4 \%)$; $p=0.034)$ although the percentage of shockable rhythms from one year to the next did not differ significantly (167 (15.0\%) vs $155(15.1 \%) ; p=0.946)$. There was also no significant difference in percentages of airway management methods (966 (88.1\%) vs $875(87 \cdot 7 \%) ; p=0.74)$, although supraglottic airway devices were used more frequently during the pandemic (157 (16•6\%) vs $201(23 \cdot 7 \%)$; $<<0.001)$. The most frequent aetiology was medical pathology, which was more common than before the pandemic (1000 (92.3\%) vs $951(89.4 \%) ; p=0.02)$.

Survival on arrival at the hospital decreased significantly during the pandemic year (387 (34.6\%) vs 313 (30.3\%); $p=0.04)$. When analysing the status of patients upon arrival at the hospital, the percentage who arrived with recovery of spontaneous circulation decreased during the pandemic (348 (31.1\%) vs $262(25.4 \%)$ ). In addition, during the pandemic and because of COVID-19, no patients were transferred for the uncontrolled non-heart beating donation programme, whereas 34 patients were transferred in the previous year. A total of 39 (3.5\%) patients arrived at the hospital undergoing CPR compared to 51 (4.9\%) the previous year.

In terms of the proportion of patients who survived to hospital discharge compared to those who were admitted, there were no significant differences; however, there was a trend to lower survival in the pandemic year (128 (12.9\%) vs. 91 (10.3\%); $p=0.07)$. One-month survival rates also did not differ significantly between the two periods but trended lower in the pandemic year (118 (12.5\%) vs 83 (9.7\%); $\mathrm{p}=0.06)$.

\section{Effect of pandemic phases on OHCA}

We also sought to assess the influence of different phases of the pandemic (three waves and one plateau after the first wave) on OHCA care (Table 2). During the plateau phase, when the 14-day cumulative incidence was less than 45 , the median age decreased, but the differences were not statistically significant $(p=0.22)$. Activation time was longer during the first wave compared to later phases $(p=0.003)$, and arrival time was longest during the first and third waves $(p=0.003)$. Sex ratios did not differ $(p=0.24)$ among the different periods. The percentage of home arrests increased significantly $(p=0.006)$ during the first wave, although with no significant changes in whether the OHCA was witnessed $(p=0.43)$ or if CPR was performed before EMS arrival $(p=0.40)$.

Table 2

Comparison by waves 


\begin{tabular}{|c|c|c|c|c|c|c|}
\hline & $\mathbf{N}$ & $\begin{array}{l}\text { 1st wave, } N= \\
298(17 \%)^{1}\end{array}$ & $\begin{array}{l}\text { Plateau, } N=350 \\
(20 \%)^{1}\end{array}$ & $\begin{array}{l}\text { 2nd wave, } N= \\
612(35 \%)^{1}\end{array}$ & $\begin{array}{l}\text { 3rd wave, } N= \\
483(28 \%)^{1}\end{array}$ & $\begin{array}{l}\text { p- } \\
\text { value }^{2}\end{array}$ \\
\hline Age (years) & 1741 & $71[61-80]$ & 68 [56-79] & 71 [56-82] & 72 [57-82] & 0.220 \\
\hline Activation time (min) & 1740 & 4:13 [2:04-9:45] & $3: 20$ [1:38-8:12] & $2: 50$ [1:25-7:10] & 3:16 [1:34-8:32] & 0.003 \\
\hline Arrival time (min) & 1738 & $\begin{array}{l}12: 31[8: 49- \\
16: 13]\end{array}$ & $\begin{array}{l}10: 49[8: 27- \\
14: 42]\end{array}$ & $\begin{array}{l}11: 55[8: 55- \\
16: 42]\end{array}$ & $\begin{array}{l}12: 41[8: 57- \\
17: 06]\end{array}$ & 0.003 \\
\hline Sex (female) & 1741 & 119 (39.9\%) & $114(32 \cdot 6 \%)$ & $215(35 \cdot 1 \%)$ & $178(37 \cdot 0 \%)$ & $0 \cdot 241$ \\
\hline Arrest location & 1735 & & & & & $<0.001$ \\
\hline Home & & $276(92 \cdot 6 \%)$ & $284(81 \cdot 1 \%)$ & $506(82 \cdot 7 \%)$ & $400(84 \cdot 2 \%)$ & \\
\hline Other & & $22(7 \cdot 4 \%)$ & $66(18 \cdot 9 \%)$ & $106(17 \cdot 3 \%)$ & $75(15 \cdot 8 \%)$ & \\
\hline Witnessed arrest & 1739 & $240(80 \cdot 5 \%)$ & $292(83 \cdot 9 \%)$ & $502(82 \cdot 2 \%)$ & $384(79 \cdot 7 \%)$ & 0.428 \\
\hline Prior CPR & 1743 & 107 (35.9\%) & $147(42 \cdot 0 \%)$ & $241(39 \cdot 4 \%)$ & $198(41 \cdot 0 \%)$ & 0.403 \\
\hline Advanced CPR & 1738 & $137(46 \cdot 0 \%)$ & $228(65 \cdot 3 \%)$ & $373(61 \cdot 1 \%)$ & $295(61 \cdot 3 \%)$ & $<0.001$ \\
\hline Reason for no CPR & 641 & & & & & 0.013 \\
\hline Arrest time unknown & & $38(24 \cdot 7 \%)$ & $30(27 \cdot 5 \%)$ & $60(28 \cdot 2 \%)$ & $52(31 \cdot 5 \%)$ & \\
\hline $\begin{array}{l}\text { Excessive interval from collapse } \\
\text { with no ALS }\end{array}$ & & $77(50 \cdot 0 \%)$ & $34(31 \cdot 2 \%)$ & $75(35 \cdot 2 \%)$ & $68(41 \cdot 2 \%)$ & \\
\hline $\begin{array}{l}\text { Status biologically } \\
\text { compromised/other }\end{array}$ & & $39(25 \cdot 3 \%)$ & $45(41 \cdot 3 \%)$ & $78(36 \cdot 6 \%)$ & $45(27 \cdot 3 \%)$ & \\
\hline Shockable rhythm over aCPR & 1024 & $17(12 \cdot 4 \%)$ & $31(13 \cdot 7 \%)$ & $57(15 \cdot 3 \%)$ & $50(17 \cdot 3 \%)$ & 0.530 \\
\hline Airway isolation over aCPR & 998 & $115(86 \cdot 5 \%)$ & $187(86 \cdot 2 \%)$ & $320(88 \cdot 2 \%)$ & $253(88 \cdot 8 \%)$ & 0.795 \\
\hline Type of isolation & 847 & & & & & $<0.001$ \\
\hline Orotracheal tube & & $73(65 \cdot 8 \%)$ & $137(77 \cdot 0 \%)$ & $225(71 \cdot 9 \%)$ & $207(84 \cdot 5 \%)$ & \\
\hline Supraglottic airways & & $37(33 \cdot 3 \%)$ & $41(23.0 \%)$ & $85(27 \cdot 2 \%)$ & $38(15 \cdot 5 \%)$ & \\
\hline Other & & $1(0 \cdot 9 \%)$ & $0(0.0 \%)$ & $3(1 \cdot 0 \%)$ & $0(0 \cdot 0 \%)$ & \\
\hline Aetiology over CPRa & 1030 & & & & & 0.307 \\
\hline Medical & & $128(94 \cdot 1 \%)$ & $204(89 \cdot 5 \%)$ & $348(93 \cdot 0 \%)$ & $271(92 \cdot 8 \%)$ & \\
\hline Non-medical & & $8(5 \cdot 9 \%)$ & $24(10 \cdot 5 \%)$ & $26(7 \cdot 0 \%)$ & $21(7 \cdot 2 \%)$ & \\
\hline Survival over CPRa & 1032 & & & & & 0.954 \\
\hline Yes & & $41(29 \cdot 9 \%)$ & $70(30 \cdot 7 \%)$ & $110(29 \cdot 4 \%)$ & $92(31 \cdot 4 \%)$ & \\
\hline No & & $96(70 \cdot 1 \%)$ & $158(69 \cdot 3 \%)$ & $264(70 \cdot 6 \%)$ & $201(68 \cdot 6 \%)$ & \\
\hline Hospital discharge over CPRa & 884 & & & & & 0.883 \\
\hline Deceased & & $109(90 \cdot 8 \%)$ & $173(88 \cdot 3 \%)$ & $282(90 \cdot 1 \%)$ & $229(89 \cdot 8 \%)$ & \\
\hline Alive & & $11(9 \cdot 2 \%)$ & $23(11 \cdot 7 \%)$ & $31(9 \cdot 9 \%)$ & $26(10 \cdot 2 \%)$ & \\
\hline One-month status over CPRa & 856 & & & & & 0.747 \\
\hline Deceased & & $109(90 \cdot 8 \%)$ & $166(88 \cdot 3 \%)$ & $276(90 \cdot 5 \%)$ & $222(91 \cdot 4 \%)$ & \\
\hline Alive & & $11(9 \cdot 2 \%)$ & $22(11 \cdot 7 \%)$ & $29(9 \cdot 5 \%)$ & $21(8 \cdot 6 \%)$ & \\
\hline${ }^{1}$ Median [IQR]; n (\%) & & & & & & \\
\hline
\end{tabular}


During the first wave, the proportion of advanced resuscitation attempts was significantly lower compared with other phases, at $46.0 \%$ vs $65.3 \%$ during the plateau, $61.1 \%$ during the second phase, and $61.3 \%$ during the third wave $(p<0.001)$. The reason for not resuscitating during the first wave was the excessive time interval from collapse to the arrival of emergency services (50.0\%), leading to a significant difference with the other phases $(p=0.013)$ (Fig. 1). There was no significant difference when comparing the percentage of shockable rhythms $(p=0.53)$ or whether the airway was managed $(p=0.79)$. Significant differences were found when comparing the type of airway management, with supraglottic airway devices used more in the first wave (33.3\%) compared to the plateau phase (23.0\%) and the second $(27.2 \%)$ and third waves $(15.5 \%$; p $<0.001)$ (Fig. 2).

The OHCA aetiology was mainly medical, with percentages ranging from $89.5 \%$ to $94.1 \%$ and no significant differences $(p=0.31)$. Similarly, no differences were found in analyses of survival on hospital arrival $(p=0.95)$ (Fig. 2). Survival to hospital discharge also did not differ across periods $(p=0.88)$ and neither did rates of one-month post-discharge survival $(p=0.74)$.

\section{Impact of the pandemic on EMS activity}

As can be seen in Figure 3, during the first wave of the pandemic, the number of calls to the emergency coordinating centre rose, increasing to 57498 calls per week, compared to 22262 in the same period of the previous year (158\% increase). During the plateau phase, the number of calls was the same as in the previous year, whereas calls increased over the pre-pandemic period in the second wave, with a peak of 11709 calls in one week. The increase intensified during the third wave, with the greatest difference at 15295 calls per week.

Despite the increase in calls to the emergency coordinating centre, the number of devices mobilised for total health emergencies did not increase during any of the pandemic phases compared to the same periods of the previous year.

\section{Discussion}

In this study, we gathered data on the OHCA care provided by the Emergency Services in the Community of Madrid, Spain, one of the first European regions to suffer the effects of COVID-19. These data have enabled a detailed analysis of OHCAs during the successive waves of the pandemic, including a plateau phase after the first wave in which strict initial mitigation measures allowed transmission to be controlled, and to compare these periods with the same months in the year prior to the pandemic. We found no increase in the number of OHCAs during the pandemic year compared to the non-pandemic year. As far as we know, no other studies have made this comparison between full years, but some groups have compared specific periods during 2020 with their counterparts in the previous year. Although a few of these investigations showed differences in the number of OHCAs, ${ }^{15}$ most reported an increase during the pandemic period. $5,6,16,17,18$

Throughout the pandemic, response times have increased, as described above, 5,19,6,20,16,17,21,22 because both resource activation and arrival times increased, as Lim et al. also reported. ${ }^{23}$ We did, however, observe response times at pre-pandemic levels during the pandemic plateau phase (Fig. 1), after which they increased again slightly.

In most studies, no significant differences were reported in terms of sex ratios, similar to our findings, but some studies have reported significantly higher patient ages during the pandemic period. ${ }^{16,18,24}$ This result contrasts with our findings and those of Rosell et al., ${ }^{25}$ in both cases showing lower ages in this patient population, although usually not significantly so. The COVID-19 pandemic has clearly influenced all aspects of life, both because of its direct health effects and because of home lockdown-related measures implemented to varying degrees. As a result, during the pandemic year, the percentage of OHCAs taking place in homes increased, 3,17,18,14,15,19,21,22,23 especially during the first wave, although this percentage later decreased, possibly because of easing lockdowns (Fig. 3).

We observed that resuscitation attempt rates decreased significantly during the first pandemic wave, as reported in other studies, 5,20,16,17,22 but we also found that they recovered to non-pandemic levels during the remainder of the pandemic year (Fig. 1), which has not been previously assessed. The most common reason for non-resuscitation, especially in the first and third waves, was the excessive time between the OHCA and the arrival of the advanced life support. These longer periods between call placement and EMS arrival in the first and third waves could be the result of both a higher number of calls and greater awareness of the need to use personal protective equipment, leading to longer call-response times.

We found no significant differences in whether or not the airway was managed, but as other studies have indicated, $, 624,25$ supraglottic airway management devices were more commonly used during the pandemic period, a pattern that changed over time (Fig. 2). Even with 
the observed changes, the use of orotracheal tubes for airway management was still more common, despite recommendations otherwise.

As other researchers have reported ${ }^{5,16,17}$ during the pandemic year, the aetiology of OHCA was most frequently medical. Only during the plateau phase did this percentage drop, falling even to non-pandemic levels (Fig. 2).

As described in other studies, 5,19,6,20,16,17,21,23,24,25,26 we found that OHCA survival at hospital admission was significantly reduced. One prediction might have been that as the first wave ended and COVID-19 incidence fell, the survival rate would have improved; however, it remained low, with no significant changes during the successive waves (Fig. 2). This pattern could be explained by the high probability of thromboembolism ${ }^{27}$ among patients who had suffered COVID-19 and its sequelae.

When comparing survival at the time of hospital discharge and comparing one-month survival rates, we found no significant differences for either between the pre-pandemic and pandemic years, but there was a trend towards worse survival during the pandemic. We also found no significant differences in these outcomes among the different periods of the pandemic.

The results of this study highlight the influence that COVID-19 has had on OHCA and on EMS activity, showing how the pandemic has increased stress on the Emergency Coordination Centre in terms of attending the population. In the community of Madrid, as in Nantes ${ }^{10}$ and Lausanne, ${ }^{28}$ the number of calls increased during the first pandemic wave, whereas some studies in other regions showed that the number of calls actually decreased. ${ }^{20,29}$ In Madrid, the increased number of EMS calls continued through the successive waves, and this overload led to a delay in activation times for available resources throughout the pandemic year. In some regions, where the calls decreased, activations often have decreased as well. ${ }^{9,20}$ In other places, however, despite an increased number of calls, resource dispatches decreased ${ }^{10}$ or remained the same, as in Madrid, ${ }^{30}$ with a similar pattern occurring during subsequent waves. One possible inference is that at times of high call volume, the various call handling systems significantly influenced how both resource dispatch and response time were handled, as Penverne et al. demonstrated. ${ }^{10}$

Limitations: This study has the limitations inherent to a prospective study starting on 15 March 2020 and involving comparison with retrospective data acquired from the SUMMA 112 OHCA registry. Although the variables were considered in the same way in all cases, some patient data may be missing, such as survival to hospital discharge and one-month survival. In addition, not knowing the underlying reason for the increase in resource mobilisation despite the increased number of calls creates a degree of uncertainty that we cannot address. Possible explanations include additional call handlers or new management guidelines. Another limitation is that according to some other studies, ${ }^{31}$ possibly only one of every ten COVID-19 positive cases was detected during the first wave, so that the actual incidence during this period could have been much higher than what official records indicate.

\section{Conclusion}

In summary, the different phases of the pandemic variably affected OHCA care. Survival from OHCA has decreased since the onset of the pandemic and has not recovered since then. The number of calls to EMS increases as Al increases, although the number of mobilizations does not.

\section{Declarations}

\section{Ethics approval and consent to participate:}

The OHSCAR registry has been approved by ethics committees in Northwestern Malaga, Aragon, Cáceres, Navarra, and the Basque Country. Informed consent was not required because the registry is anonymised. STROBE guidelines for data reporting were followed.

\section{Consent for publication:}

Not applicable.

\section{Availability of data and materials:}

The anonymised data on the participants included in this study will be made available on request. Researchers should submit a proposal for data analysis in line with the overall objectives of the project. The data will be available from the date of publication of this article for 
a period of 36 months. Proposals should be addressed to the corresponding author.

\section{Competing interests:}

The authors declare that they have no competing interests.

\section{Funding:}

None specific to this study.

\section{Authors' contributions:}

Jose $\mathrm{M}^{\mathrm{a}}$ Navalpotro and Diana Monge designed the study. Jose $\mathrm{M}^{\mathrm{a}}$ Navalpoptro, Alonso Mateos, and Carlos Alonso coordinated the study and verified the data. Diana Monge and Fernando Neria performed and supervised the statistical analysis. Manuel José González and Belén Muñoz participated in the literature search. Fernando Neria and Manuel José González participated in data analysis and table and figure design. Jose $M^{a}$ Navalpotro, Manuel José González, Belén Muñoz, Alfredo Carrillo, Yago Muñecas, Juan Les, and Francisco Peinado contributed to the development of the study and the data collection. All authors critically reviewed and approved the final version. All authors had full access to all study data and take the ultimate responsibility for the decision to submit this paper for publication.

\section{Acknowledgments:}

The study has been edited and proofread by San Francisco Edit, the cost of which has been met by Vygon.

\section{References}

1. World Health Organization (WHO). Alocución de apertura del Director General de la OMS en la rueda de prensa sobre la COVID-19 celebrada el 11 de marzo de 2020. Discursos del Dir Gen la OMS [Internet]. 2020 [cited 2020 May 29];1. Available from: https://www.who.int/es/dg/speeches/detail/who-director-general-s-opening-remarks-at-the-media-briefing-on-covid-19-11-march2020

2. Secretaria General de Sanidad. Centro de Coordinación de Alertas y Emergencias Sanitarias [Internet]. Ministerio de Sanidad Gobierno de España. 2021. p. 1-2. Available from: https://www.mscbs.gob.es/profesionales/saludPublica/ccayes/alertasActual/nCov/documentos/Actualizacion_44_COVID_1200.pdf

3. Benjamin EJ, Muntner P, Alonso A, Bittencourt MS, Callaway CW, Carson AP, et al. Heart Disease and Stroke Statistics-2019 Update: A Report From the American Heart Association. Vol. 139, Circulation. 2019. 56-528 p.

4. Gräsner JT, Wnent J, Herlitz J, Perkins GD, Lefering R, Tjelmeland I, et al. Survival after out-of-hospital cardiac arrest in Europe Results of the EuReCa TWO study. Resuscitation. 2020;148:218-26.

5. Baldi E, Sechi GM, Mare C, Canevari F, Brancaglione A, Primi R, et al. COVID-19 kills at home: the close relationship between the epidemic and the increase of out-of-hospital cardiac arrests. Eur Heart J [Internet]. 2020 [cited 2020 Jul 9]; Available from: https://pubmed.ncbi.nlm.nih.gov/32562486/

6. Lai PH, Lancet EA, Weiden MD, Weiden MD, Webber MP, Webber MP, et al. Characteristics Associated with Out-of-Hospital Cardiac Arrests and Resuscitations during the Novel Coronavirus Disease 2019 Pandemic in New York City. JAMA Cardiol [Internet]. 2020 [cited 2020 Jul 9]; Available from: /pmc/articles/PMC7305567/?report=abstract

7. Baldi E, Primi R, Gentile FR, Mare C, Centineo P, Palo A, et al.Out-of-hospital cardiac arrest incidence in the different phases of COVID19 outbreak. Resuscitation [Internet]. 2021;159:115-6. Available from: https://doi.org/10.1016/j.resuscitation.2020.12.020

8. Sultanian P, Lundgren P, Strömsöe A, Aune S, Bergström G, Hagberg E, et al. Cardiac arrest in COVID-19: Characteristics and outcomes of in- And out-of-hospital cardiac arrest. A report from the Swedish Registry for Cardiopulmonary Resuscitation. Eur Heart $\mathrm{J}$ [Internet]. 2021;42(11):1094-106. Available from: https://academic.oup.com/eurheartj/article/42/11/1107/6128748

9. Kovach CP, Perman SM. Impact of the COVID-19 pandemic on cardiac arrest systems of care. Curr Opin Crit Care. 2021;Publish Ah:239-45.

Page $9 / 12$ 
10. Penverne Y, Leclere B, Labady J, Berthier F, Jenvrin J, Javaudin F, et al. Impact of two-level filtering on emergency medical communication center triage during the COVID-19 pandemic: An uncontrolled before-after study. Scand J Trauma Resusc Emerg Med [Internet]. 2020;28(1). Available from: https://doi.org/10.1186/s13049-020-00775-0

11. Secretaria General de Sanidad. Centro de Coordinación de Alertas y Emergencias Sanitarias [Internet]. Ministerio de Sanidad Gobierno de España. 2021. p. 1-2. Available from: https://www.mscbs.gob.es/profesionales/saludPublica/ccayes/alertasActual/nCov/documentos/Actualizacion_223_COVID-19.pdf

12. Rosell-Ortiz F, Escalada-Roig X, Fernández Del Valle P, Sánchez-Santos L, Navalpotro-Pascual JM, Echarri-Sucunza A, et al.Out-ofhospital cardiac arrest (OHCA) attended by mobile emergency teams with a physician on board. Results of the Spanish OHCA Registry (OSHCAR). Resuscitation [Internet]. 2017 Apr;113:90-5. Available from: http://www.ncbi.nlm.nih.gov/pubmed/28202420

13. Perkins GD, Jacobs IG, Nadkarni VM, Berg RA, Bhanji F, Biarent D, et al. Cardiac arrest and cardiopulmonary resuscitation outcome reports: Update of the Utstein resuscitation registry templates for out-of-hospital cardiac arrest: A statement for healthcare professionals from a task force of the international liaison committee . Circulation. 2015;132(13):1286-300.

14. Von Elm E, Altman DG, Egger M, Pocock SJ, Gøtzsche PC, Vandenbrouckef JP. The Strengthening the Reporting of Observational Studies in Epidemiology (STROBE) Statement: Guidelines for reporting observational studies. Bull World Health Organ. 2007;85(11):867-72.

15. Huber BC, Brunner S, Schlichtiger J, Kanz KG, Bogner-Flatz V. Out-of-hospital cardiac arrest incidence during COVID-19 pandemic in Southern Germany. Resuscitation [Internet]. 2020;157:121-2. Available from: https://doi.org/10.1016/j.resuscitation.2020.10.034

16. Fothergill RT, Smith AL, Wrigley F, Perkins GD. Out-of-Hospital Cardiac Arrest in London during the COVID-19 pandemic. Resusc Plus [Internet]. 2021;5(November):100066. Available from: https://doi.org/10.1016/j.resplu.2020.100066

17. Baldi E, Sechi GM, Mare C, Canevari F, Brancaglione A, Primi R, et al. Treatment of out-of-hospital cardiac arrest in the COVID-19 era: A 100 days experience from the Lombardy region. PLoS One [Internet]. 2020;15(10). Available from: https://doi.org/10.1371/journal.pone.0241028

18. Mathew S, Harrison N, Chalek AD, Gorelick D, Brennan E, Wise S, et al. Effects of the COVID-19 pandemic on out-of-hospital cardiac arrest care in Detroit. Am J Emerg Med [Internet]. 2021;46:90-6. Available from: https://doi.org/10.1016/j.ajem.2021.03.025

19. Marijon E, Karam N, Jost D, Perrot D, Frattini B, Derkenne C, et al. Out-of-hospital cardiac arrest during the COVID-19 pandemic in Paris, France: a population-based, observational study. Lancet Public Heal. 2020;5(8):e437-43.

20. Ball J, Nehme Z, Bernard S, Stub D, Stephenson M, Smith K. Collateral damage: Hidden impact of the COVID-19 pandemic on the outof-hospital cardiac arrest system-of-care. Resuscitation [Internet]. 2020 Nov 1;156:157-63. Available from: https://doi.org/10.1016/j.resuscitation.2020.09.017

21. Baldi E, Sechi GM, Mare C, Canevari F, Brancaglione A, Primi R, et al. Out-of-Hospital Cardiac Arrest during the Covid-19 Outbreak in Italy. N Engl J Med [Internet]. 2020 Apr 29;NEJMc2010418. Available from: http://www.nejm.org/doi/10.1056/NEJMc2010418

22. Paoli A, Brischigliaro L, Scquizzato T, Favaretto A, Spagna A. Out-of-hospital cardiac arrest during the COVID-19 pandemic in the Province of Padua, Northeast Italy. Resuscitation. 2020;154:47-9.

23. Lim SL, Shahidah N, Saffari SE, Ng QX, Ho AFW, Leong BSH, et al. Impact of covid-19 on out-of-hospital cardiac arrest in Singapore. Int J Environ Res Public Health [Internet]. 2021;18(7). Available from: https://doi.org/10.3390/ijerph18073646

24. Nishiyama C, Kiyohara K, Iwami T, Hayashida S, Kiguchi T, Matsuyama T, et al. Influence of COVID-19 pandemic on bystander interventions, emergency medical service activities, and patient outcomes in out-of-hospital cardiac arrest in Osaka City, Japan. Resusc Plus [Internet]. 2021;5(November 2020):100088.Available from: https://doi.org/10.1016/j.resplu.2021.100088

25. Rosell Ortiz F, Fernández del Valle P, Knox EC, Jiménez Fábrega X, Navalpotro Pascual JM, Mateo Rodríguez I, et al.Influence of the Covid-19 pandemic on out-of-hospital cardiac arrest. A Spanish nationwide prospective cohort study. Resuscitation. 2020;157(September):230-40.

26. Chan PS, Girotra S, Tang Y, Al-Araji R, Nallamothu BK, McNally B. Outcomes for Out-of-Hospital Cardiac Arrest in the United States during the Coronavirus Disease 2019 Pandemic. JAMA Cardiol [Internet]. 2021;6(3):296-303. Available from: https://jamanetwork.com/

27. Aktaa S, Wu J, Nadarajah R, Rashid M, de Belder M, Deanfield J, et al. Incidence and mortality due to thromboembolic events during the COVID-19 pandemic: Multi-sourced population-based health records cohort study. Thromb Res [Internet]. 2021;202(March):1723. Available from: https://doi.org/10.1016/j.thromres.2021.03.006

28. Dami F, Berthoz V. Lausanne medical dispatch centre's response to COVID-19. Scand J Trauma Resusc Emerg Med [Internet]. 2020;28(1). Available from: https://doi.org/10.1186/s13049-020-00735-8

Page $10 / 12$ 
29. Lerner EB, Newgard CD, Mann NC. Effect of the Coronavirus Disease 2019 (COVID-19) Pandemic on the U.S. Emergency Medical Services System: A Preliminary Report.Acad Emerg Med [Internet]. 2020;27(8):693-9. Available from: www.aemj.org

30. Navalpotro-Pascual JM, Fernández Pérez C, Peinado Vallejo FA, Carrillo Moya A, Muñecas Cuesta Y, Muñoz Isabel B, et al. Actividad y asistencia a la parada cardiorrespiratoria en un servicio extrahospitalario de emergencias durante la pandemia COVID-19.

Emergencias Rev la Soc Esp Med Emergencias [Internet]. 2021;33(2):100-6. Available from:

http://emergencias.portalsemes.org/descargar/actividad-y-asistencia-a-la-parada-cardiorrespiratoria-en-un-servicio-extrahospitalariode-emergencias-durante-la-pandemia-covid19/

31. Delgado A. Estimación de casos por COVID-19 en España durante la primera ola con respecto al principio de la segunda. Available from: https://www.datadista.com/coronavirus/estimacion-diagnostico-segunda-ola-covid19/

\section{Figures}

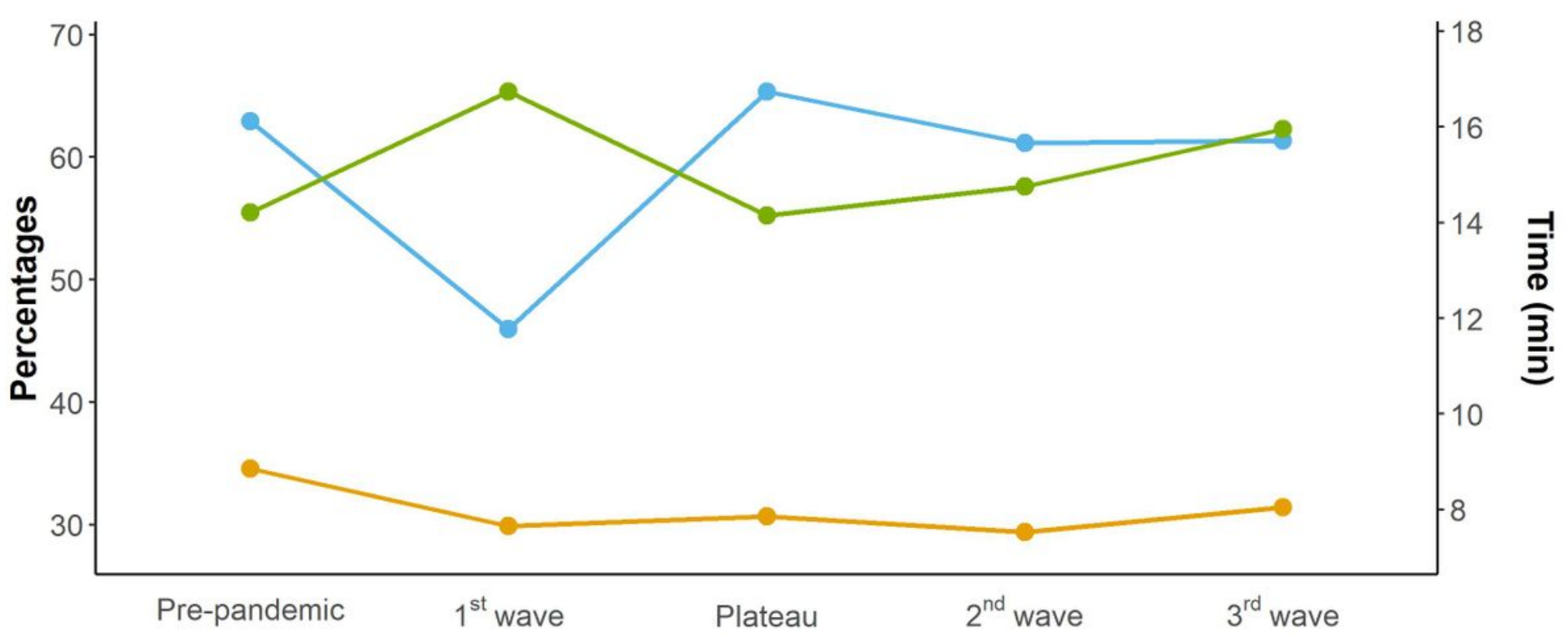

- aCPR attempts - Survival over aCPR - Response time

\section{Figure 1}

Response time in minutes and seconds and percentage of aCPR attempts and survival upon arrival at hospital. 


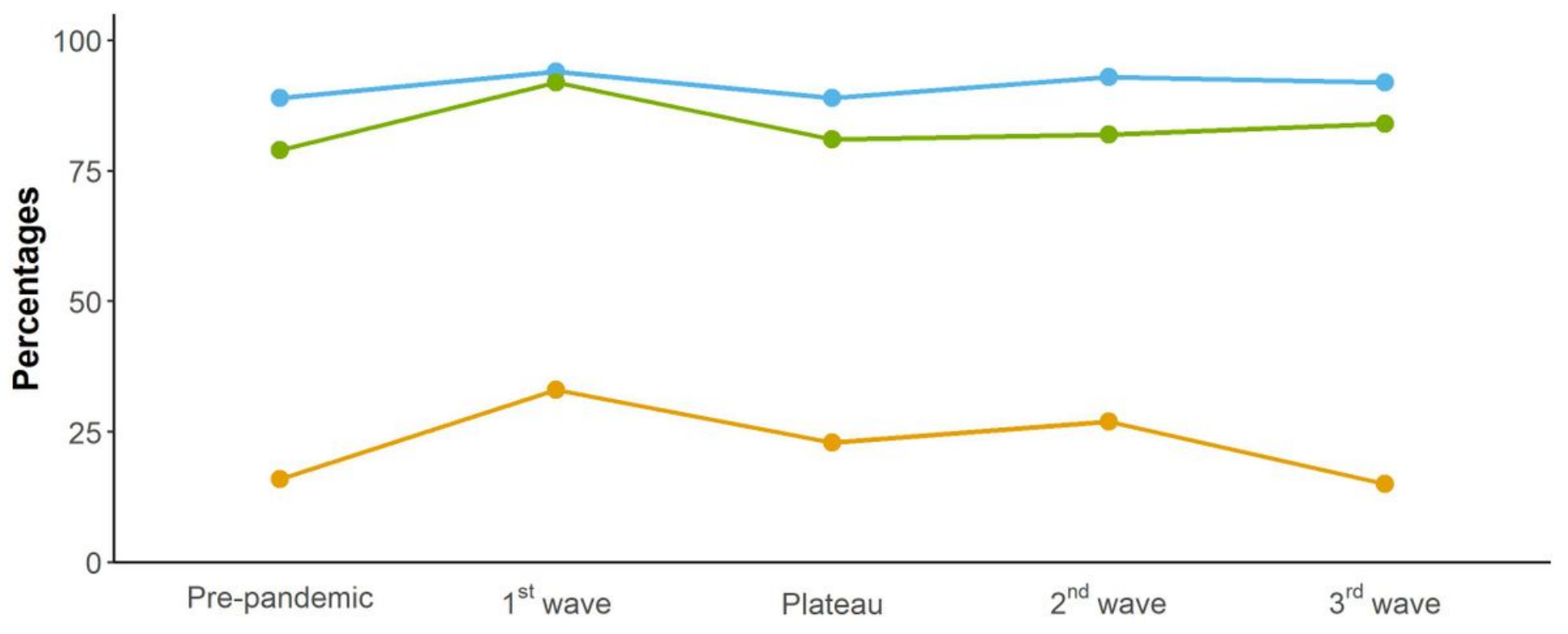

- Medical aetiology - Supraglottic devices - Home arrests

\section{Figure 2}

Percentage of cases at home, use of supraglottic airway devices, and medical aetiology.

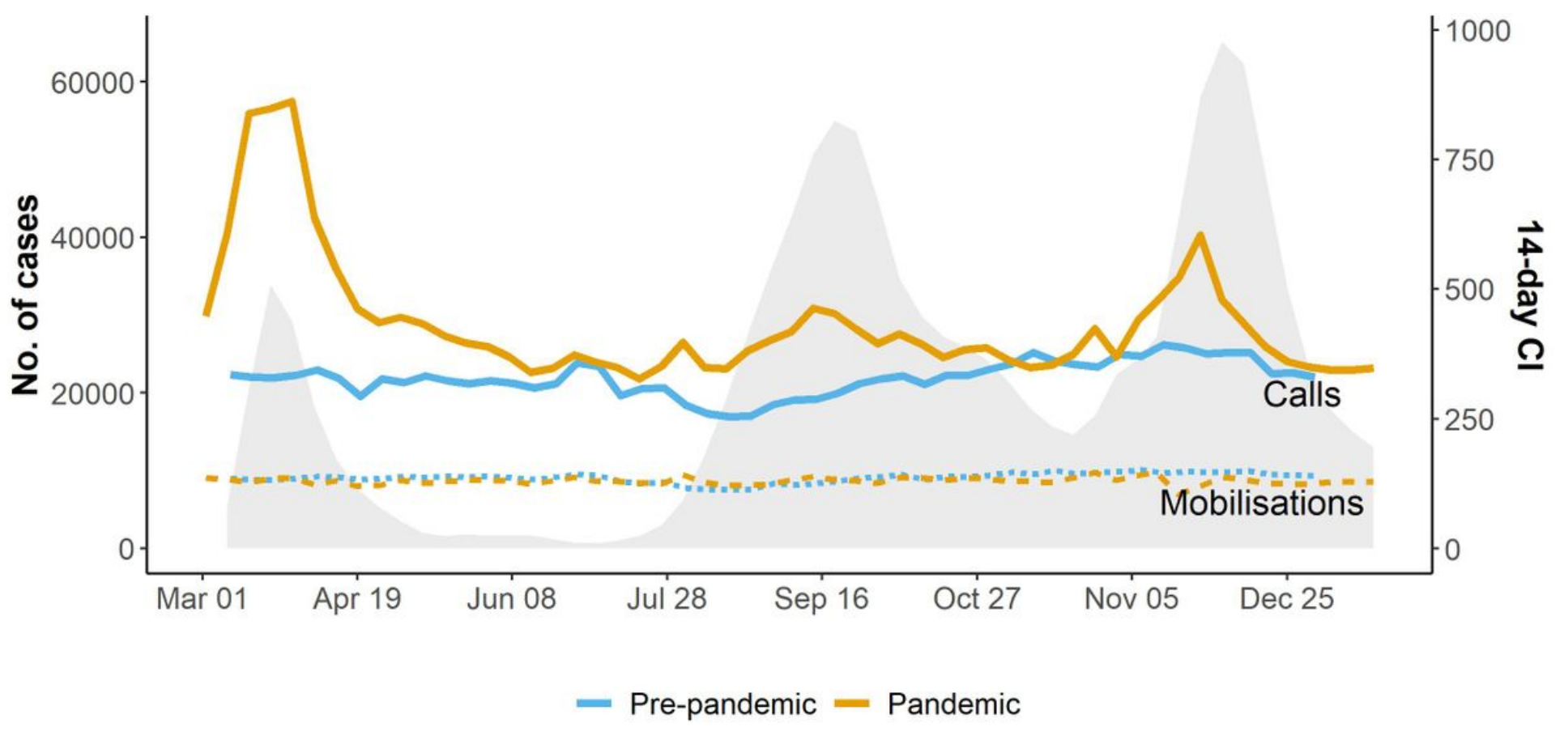

Figure 3

Number of calls and mobilisations per 14-day cumulative incidence period during the pandemic. 